\title{
DESIGN AND CONSTRUCTION OF SUGARCANE JUICE EXTRACTING MACHINE FOR RURAL COMMUNITY
}

\author{
Uti Joseph Nduka, Adogbeji Victor Omoefe \\ Mechanical Engineering Department, \\ Moshood Abiola Polytechnic Abeokuta Ogun State Nigeria \\ Akinola Adebisi Olayinka \\ Mechanical Engineering Department, \\ Federal University of Technology Akure Ondo State Nigeria
}

\begin{abstract}
Extracting the juice from sugarcane has been a major problem, especially with the use of a traditional way that could damage the gum of the teeth and putting the human teeth in distress and require much energy. The main objective of the project is to design a sugarcane juice extracting machine, that will extract juice from sugarcane and that will separate the juice from the sugarcane and the bagasse. The crushing unit is made of two rollers which are $134 \mathrm{~mm}$ thick diameter and length of $265 \mathrm{~mm}$, with crushing section of the roller of $17.8 \mathrm{~mm}$ length and the cutting blade section of the roller $8.7 \mathrm{~mm}, 148 \mathrm{~mm}$ long hollow stainless steel cylinders and stainless steel rods of $32 \mathrm{~mm}$ diameter. The machine was constructed by several well-established methods such as methods, such are as follows: Measuring, Marking Out Operation, Cutting Operation, Welding Operation, Grinding Operation. The machine was tested using a given sample of sugarcane weighing $22.5 \mathrm{~kg}$, the mass of juice extracted was $4.1 \mathrm{~kg}$, while the extraction took about 22 min. From the design, the axial deflection of the crusher is $3.540 \times 10^{5} \mathrm{~m}$ with an actual speed of the roller of $10.5 \mathrm{rpm}$. The design of the sugarcane juice extracting machine possesses simplicity in operation and maintenance as well as affordable with low running and maintenance costs with reliable efficiency.
\end{abstract}

Keywords: Sugarcane, Extractor. Extraction Efficiency

\section{INTRODUCTION}

The sugarcane plant is the common name of a species of herb belonging to the grass family. There are three major categories of sugarcane found in Nigeria and namely saccharrim, offiicinarum, and Sporitaneum. It is of six perennial kinds of grass species in the tribe andropogonee of the geranium (porseglove, 1988).

Extracting the juice from sugarcane through the use of a traditional way could damage the gum of the teeth and putting the human teeth in distress and require much energy as a major problem. The quantity of the extracted juice produce from the traditional way will not be sufficient enough. The design of a sugarcane extracting machine, which is made of two stainless steel roller crushers, will be able to extract enough sufficient juice without putting pressure on the machine. The main objective of the project is to design and construction of sugarcane juice extracting machine, extraction of juice from sugarcane, separation of juice from the sugarcane and the bagasse.

\section{LITERATURE REVIEW}

The development of sugarcane machines has been started hundreds of years back in many countries. The Trapiche is a traditional wooden roller used by people of Panama and Columbia to extract sugarcane juice, the trapiche is a Spanish word "sugarcane crusher". It is varying in size which is made up of wood. It has two rollers that are vertically placed and held by a wooden frame. (Rika, 2010). 
A sugar cane juice extractor machine is a machine used to extract the juice from sugar cane. These juice extractor machines were built to help human extract the juice from sugar cane through crushing and rolling process.

A conventional machine is a simple machine consists of several gears, rollers, and lever attached on a cast-iron chassis body. Most conventional machines are made up of cast iron material which is strong and durable. These machines were made by a simple mechanism of rolling and crushing (Kulkarni, 2005).

Crushing a sugar cane requires strong force due to its strong and hard characteristics. Juice extractor machines were built mostly focused on the mechanical of the machine. The efficiency of the machine depends on the mechanical system that has been designed on the machine. Mechanical power is the most essential needs in these identified areas (Olaoye, 2011).

According to Cesar B.G.C (2004), designed conveyed screw press conveyors that gently squeeze the fiber (sugarcane) in each stage, improving extraction. The performance of a pilotscale screw-press conveyor was tested for dewatering capabilities and power consumption. The un-optimized equipment decreased megasse moisture from 96 to $89 \%$.

Olaoye, J. O. (2011), developed a sugarcane juice extractor for small scale industries. The designed is a simple mechanical device for the extraction of sugarcane juice. The output capacities of 10.50 , 12.00 and $14.25 \mathrm{~kg} / \mathrm{hr}$ were obtained at operating speeds of $0.25,0.3$ and $0.36 \mathrm{~m} / \mathrm{s}$. The extraction efficiency of the machine ranged between 40 and 61 $\%$ at operating speeds of 0.25 and $0.36 \mathrm{~m} / \mathrm{s}$. He observed that this optimum performance of the machine cannot be sustained over a long processing period due to the bluntness development of the perforated grating drum over time.

\section{MATERIALS AND METHODS}

An extracting machine was designed and fabricated. The materials use for the design and fabrication of the sugarcane juice extractor was locally sourced, Stainless steel Plate, Rollers, stainless square pipe, gears, chain, bearing, electric motor, reduction gear, bolt, and nut were bought-out materials were used. In the design, stainless steel material was used to avoid contamination of the extracted juice. The machine was designed to extract juice from the sugarcane and it is powered by an electric motor.
The rollers are made of two parts which are the slicing part and the crushing unit.

The machine was mounted on a table made from square stainless pipes and angle bar, with the electric motor and reduction gear mounted on the base, the designed roller was assembling and coupled with the shaft in the crushing chamber and the pinion gears were used on both sides of the rollers to connect to a chain drive.

\section{MACHINE DESCRIPTION \& OPERATION}

The crushing unit is made of two rollers which are $134 \mathrm{~mm}$ thick diameter and length of $26.5 \mathrm{~mm}$, with crushing section of the roller of $17.8 \mathrm{~mm}$ length and the cutting blade section of the roller $8.7 \mathrm{~mm}, 148$ $\mathrm{mm}$ long hollow stainless steel cylinders and stainless steel rods of $32 \mathrm{~mm}$ diameter. The crushing surface of the roller is of two dimensions; one part is smaller and it is supported with cutting blades that serve as a cutter while the other is bigger and it has a rough surface with a depth of $5 \mathrm{~mm}$ which then compresses the sugarcane after being cut. The clearance between the two rollers is 15 $\mathrm{mm}$. The two-shaft used on each of the crushing rollers is carried by a shaft having a diameter of $28.8 \mathrm{~mm}$ and a length of $511 \mathrm{~mm}$ for the upper shaft and the lower shaft, diameter $28.8 \mathrm{~mm}$ and length of $460 \mathrm{~mm}$.

\section{DESIGN ANALYSIS OF SUGARCANE JUICE EXTRACTING MACHINE}

\section{a. Power Selection For Motor}

The required power for the electric motor was calculated using equation (1) (Alexandr et al., 2010)

Power required $(\mathrm{P})=\mathrm{T} \omega$

Where

$\mathrm{T}$ is the torque in $(\mathrm{N} / \mathrm{m})$

$P$ is the transmitted power in watt

$\omega$ is the angular speed

$\mathrm{P}=14.7 \times 151.86$

$\mathrm{P}=2232.3$

$\mathrm{P}=2.2323 \mathrm{hp}$

However, a $3.0 \mathrm{hp}$ motor of $1450 \mathrm{rpm}$ was chosen

b. Determination of Actual Motor Torque

The actual motor torque $\left(\mathrm{T}_{\mathrm{m}}\right)$ was obtained using equation (2) (Alexandr et al., 2010) 


\section{International Journal of Engineering Applied Sciences and Technology, 2019 \\ Vol. 4, Issue 4, ISSN No. 2455-2143, Pages 306-311 \\ Published Online August 2019 in IJEAST (http://www.ijeast.com)}

Motor Torque, $\mathrm{T}_{\mathrm{m}}=\frac{\text { Motor Power }}{\text { Angular Velocity }}$

where

Motor Power is 2232.2

Angular velocity is 151.86

Motor Torque $\frac{2232.3}{151.86}$

$\mathrm{T}_{\mathrm{m}}=14.7 \mathrm{Nm}$

The Actual Motor Torque was 14.7 Nm

\section{c. The Chain Drive}

The required chain drive was calculated using equation (3) (Khurmi \& Gupta 2010)

Design power per a strand $=$ Transmitted Power $\times$ Service Power

where no.of the stand

Transmitted Power is $2237 \mathrm{~kW}$

Service Power is 1.3

$$
\begin{array}{r}
\text { Design power per strand }=\frac{2237 \times 1.3}{1} \\
=2908.1 \mathrm{~kW} / \text { Strand }
\end{array}
$$

Hence Design power per strand is $2908.1 \mathrm{~kW}$

$$
\text { /Strand }
$$

\section{d. The Actual Speed of the Roller:}

The actual speed of the rollers was obtained using equation (4) (Khurmi \& Gupta 2010)

$$
\eta 2=\eta_{1}\left(\frac{N_{1}}{N_{2}}\right)
$$

where

$\mathrm{n}_{1}$ is the speed of driver which is $28.4 \mathrm{rpm}$

$\mathrm{n}_{2}$ is the speed of the roller

$\mathrm{N}_{1}$ is the speed of rotation of smaller sprocket in rpm, which is $28.4 \mathrm{rpm}$

$\mathrm{N}_{2}$ is the speed of rotation of larger sprocket in rpm, which is $75.3 \mathrm{rpm}$

$\mathrm{n}_{1}=28.4 \times \frac{28.4}{75.3}$

$\mathrm{n}_{2}=28.4(0.377)$

$\mathrm{n}_{2}=10.7 \mathrm{rpm}$

\section{e. Tangential Driving Force $\left(\mathbf{F}_{\mathrm{T}}\right)$}

The required tangential driving force was calculated using equation (5) (Khurmi \& Gupta 2010)

$F_{T}=\frac{\text { Power Transmitted (in watt) }}{\text { Speed of Chain (m/s) }}$

where

$\mathrm{F}_{\mathrm{T}}$ is the tangential driving force
$\mathrm{P}$ is the power transmitted in watt, which is 2237 watt

$\mathrm{V}$ is the speed of chain, which is $0.45 \mathrm{~m} / \mathrm{s}$

$F_{T}=\frac{2237}{0.45}$

$\mathrm{F}_{\mathrm{T}}=4.97$

\section{f. Power Transmitted by Chain}

The power transmitted by the chain basis on breaking load was calculated from equation (6) (Khurmi \& Gupta 2010)

$\mathrm{Sf}=\frac{\mathrm{WB} \times \mathrm{V}}{\mathrm{n} \times \mathrm{Ks}}$

where

$\mathrm{W}_{\mathrm{B}}$ is the braking load in newton, which is $8971 \mathrm{~N}$

$\mathrm{V}$ is the velocity of the chain in $\mathrm{m} / \mathrm{s}$, which is 0.45 $\mathrm{m} / \mathrm{s}$

$\mathrm{n}$ is the factor of safety which is 30.7

$\mathrm{Ks}$ is the Service factor $\mathrm{K}_{1} \times \mathrm{K}_{2} \times \mathrm{K}_{3}$

$\mathrm{K}_{1}$ is the load factor, which is $1.25, \mathrm{~K}_{2}$ is the lubrication factor, which is $1.5, \mathrm{~K}_{3}$ is the rating factor, which is 1

$\mathrm{Sf}$ is the power transmitted by a chain

$\mathrm{P}=\frac{8971 \times 0.45}{30.7 \times 1.875}=\frac{4036.95}{57.5625}=70.1 \mathrm{watt}$

$\mathrm{P}=70.1$ watt

\section{g. Shaft Design}

Torque (T) transmitted by the shaft is calculated from equation (7) (Khurmi \& Gupta 2010)

$$
\mathrm{T}=\frac{\mathrm{P} \times 60}{2 \pi \mathrm{N}}
$$

where

$\mathrm{T}$ is the torque in $(\mathrm{N} / \mathrm{m})$

$\mathrm{p}$ is the transmitted power in watt, which is 2237 watt

$\mathrm{N}$ is the Speed of Shaft in rpm, which is $1450 \mathrm{rpm}$

$\mathrm{T}=\frac{2237 \times 60}{2 \times 3.142}=\frac{134220}{9111.8}$

$\mathrm{T}=14.7 \mathrm{~N} / \mathrm{m}$

\section{h. Allowable Shear Stress}

The required allowable shear stress was calculated using equation (8) (Khurmi \& Gupta 2010)

$$
\tau=\frac{\mathrm{Tu}}{\mathrm{Fs}}=\frac{\text { Ultimate Shear Stress for Steel }}{\text { Factor of Safety }}
$$

where

$\tau$ is the stress

$\mathrm{Tu}$ is the Ultimate Shear Stress for Steel is 360 $\mathrm{MPa}$ 
$\mathrm{F}_{\mathrm{s}}$ is the Factor of Safety is 8

$$
\begin{aligned}
\tau=\frac{360 \mathrm{mph}}{8}=45 \mathrm{~N} / \mathrm{mm} \\
\tau=45 \mathrm{~N} / \mathrm{mm}
\end{aligned}
$$

\section{i. $\quad$ Torque twisting moment by a solid} shaft

The required torque twisting moment by the solid shaft was calculated using equation (9) (Khurmi \& Gupta 2010)

$T e=\frac{\pi}{16} \times \tau \times d^{3}$

where

$\tau$ is the Shear Stress, which is $45 \mathrm{~N}$

$\mathrm{T}_{e}$ is the Twist moment

$\mathrm{d}$ is the diameter

$14.7 \times 10^{3}=\frac{3.142}{16} \times 45 \times d^{3}$

$14.7 \times 10^{3}=8.84 d^{3}$

$d^{3}=\frac{14.7 \times 10^{3}}{8.84}$

The diameter of the solid shaft is $11.84 \mathrm{~mm}$

Shaft diameter, $\mathrm{d}$ is $12 \mathrm{~mm}$

\section{j. Design Analysis of Crusher}

The required design analysis of the crusher was obtained from equation (10) (Tipler, 2004)

$\mathrm{F}_{\mathrm{c}}=\mathrm{M}_{\mathrm{f}} \times \mathrm{S}_{\mathrm{f}}$

where

$\mathrm{F}_{\mathrm{c}}$ is the crushing of the design

$\mathrm{M}_{\mathrm{f}}$ is the Mass of Roller, which is $220 \mathrm{~N}$

$\mathrm{S}_{\mathrm{f}}$ is the factor of safety, which is 1.7

$\mathrm{F}_{\mathrm{c}}=220 \times 1.7$

\section{$F_{c}$ is 374}

\section{k. Torque Transmitted to the Crusher}

The torque transmitted to the crusher was calculated from equation (11) (Tipler, 2004)

$\mathrm{T}=\mathrm{F} \times \mathrm{r}$

where

$\mathrm{T}$ is the torque

$\mathrm{F}$ is the Force, which is $374 \mathrm{~N}$

$\mathrm{r}$ is the radius of crusher which is 0.068

$\mathrm{T}=374 \times 0.068$

$\mathrm{T}=25.432 \mathrm{~N}$

Hence Torque Transmitted to the Crusher is 25.432 $\mathrm{N}$
1. Permissible Angle of Twist for Crusher

The required Permissible Angle of Twist for Crusher was calculated from equation (12) \& (13) (Abdulkadir et al. 2009)

$\theta=\frac{584 \mathrm{MtL}}{\mathrm{Gd} 4}$ (For Solid Circular Shaft)

But $\mathrm{M}_{\mathrm{t}}=\frac{\mathrm{P} \times 9550}{\mathrm{~N}}(\mathrm{Nm})$

where

$\theta$ is the angle of twist

$\mathrm{L}$ is the length of the roller, which is $0.265 \mathrm{~m}$

$\mathrm{G}$ is the modulus of rigidity for steel, which is $80 \mathrm{x}$ $10^{9} \mathrm{Nm}^{2}$

$\mathrm{P}$ is the power transmitted which is $2.2371 \mathrm{~kW}$

$\mathrm{N}$ is the speed of the shaft, which is $1450 \mathrm{rpm}$

$\mathrm{d}$ is the diameter which is $0.134 \mathrm{~m}$

$\mathrm{M}_{\mathrm{t}}$ is the moment of twist of the crusher, which is $14734 \mathrm{Nm}$

$\mathrm{Mt}=\frac{2.2371 \times 9550 \times 1000}{1450}=\frac{21364305}{1450}$

$\mathrm{Mt}=14734 \mathrm{Nm}$

$\theta=\frac{584 \mathrm{MtL}}{\mathrm{Gd} 4}$

$=\frac{584 \times 14734 \times 0.265}{80 \times 10^{9} \times(0.134)^{4}}=\frac{280233.84}{25793434.8}$

$=0.088^{\circ}$

Hence the Permissible Angle of Twist for Crusher is $0.088^{\circ}$

m. Axial Deflection of Crusher

The axial deflection of the crusher was calculated from equation (14) (Abdulkadir et al., 2009)

$ð \mathrm{~L}=\frac{\mathrm{FL}}{\mathrm{AE}}$

where

$ð \mathrm{~L}$ is the axial deflection

$A$ is the area of crusher

$\mathrm{L}$ is the length of the roller, which is $0.265 \mathrm{~m}$

$\mathrm{E}$ is the modulus of elasticity, which is $200 \times 10^{3}$

$\mathrm{N} / \mathrm{mm}^{2}$

$\mathrm{D}$ is the diameter of the roller, which is $0.134 \mathrm{~m}$

$\mathrm{F}$ is the Force of the crusher

Area of Crusher, $\mathrm{A}=\frac{\pi D^{2}}{4}$

$\mathrm{A}=\frac{3.142 \times 0.134^{2}}{4}$

$\mathrm{A}=0.014 \mathrm{~m}^{2}$ 
$ð \mathrm{~L}=\frac{374 \times 0.265}{0.014 \times 200 \times 10^{4}}$

$ð \mathrm{~L}=3.540 \times 10^{-5} \mathrm{~m}$

\section{n. Extraction Efficiency of Machine}

Extraction Efficiency Machine was measured the ratio of the weight of the extracted juice to the total weight of sugarcane as determined below

$\frac{\text { Weight of Extracted Juice }}{\text { Total Weight of Sugarcane }} \times 100$

Total Weight of stalks (Sugarcane) is given by (mass of shredded stalks - a mass of dry bagasse)

$=\frac{4.1 \mathrm{~kg}}{22.5-17.6 \mathrm{~kg}} \times 100$

$\frac{4.1 \mathrm{~kg}}{4.9 \mathrm{~kg}} \times 100$

$=0.84 \times 100$

$83.7 \%$

\section{o. Performance Evaluation}

The machine was tested using a given sample of cane stalks weighing $22.5 \mathrm{~kg}$; the machine was evaluated using the following indicators and the results of the test are:

Capacity (Throughput) of Machine was based on the ability of the machine to extract sugarcane juice of duration of time per kilogram weight of the sugarcane

$$
\begin{aligned}
& =\frac{\text { Weight of Sugarcane }}{\text { Duration of extraction in min }} \times \frac{60 \mathrm{~min}}{1 \mathrm{hr}} \\
& =\frac{22.5 \mathrm{~kg}}{22 \mathrm{~min}} \times \frac{60 \mathrm{~min}}{1 \mathrm{hr}} \\
& =\frac{1350 \mathrm{~kg}}{22 \mathrm{hr}}
\end{aligned}
$$

\section{$61.36 \mathrm{~kg} / \mathrm{hr}$}
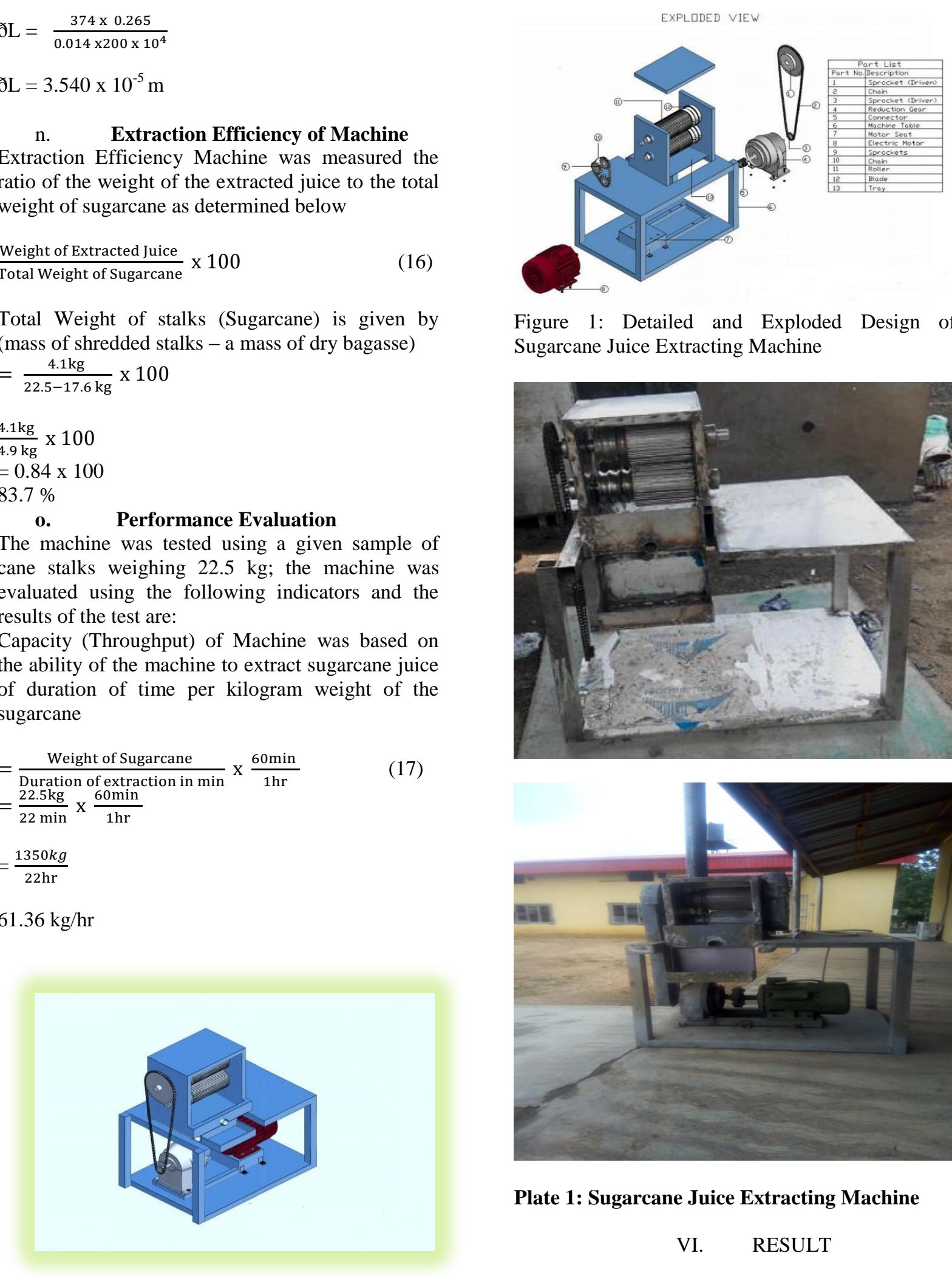

Figure 1: Detailed and Exploded Design of Sugarcane Juice Extracting Machine

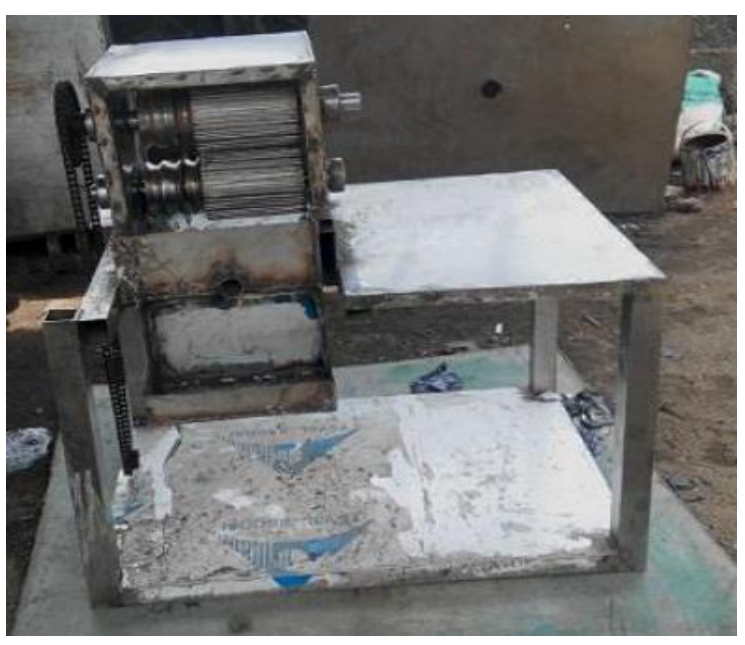

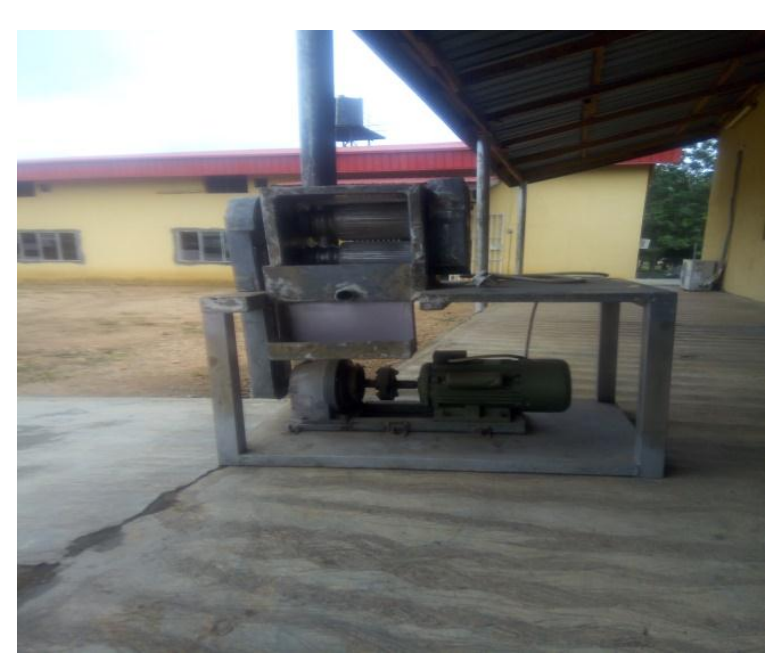

Plate 1: Sugarcane Juice Extracting Machine

VI. RESULT 
From the design analysis of the sugarcane juice extracting machine, the machine will require an electric motor of $3 \mathrm{hp}$ with speed of $1450 \mathrm{rpm}$ that would be connected to a reduction gear motor that will reduce the motor speed from $1450 \mathrm{rpm}$ to 28.4 rpm of the crushing rollers, with an actual speed of the rollers $10.5 \mathrm{rpm}$ and the crusher having the permissible angle of twist of $0.0088^{\circ}$ and the torque transmitted to the crusher $25.432 \mathrm{~N}$, having an axial deflection of the crusher $3.540 \times 10^{5} \mathrm{~m}$. The sugarcane juice extractor performs optimally with an efficiency of about $84 \%$ when using an electric motor of 3HP and a reduction gear to reduce the speed of the electric motor that will reduce the roller speed to about $28 . .81 \mathrm{rpm}$.

The machine was tested using a sample of sugarcane weighing $22.5 \mathrm{~kg}$, and the mass of juice extracted was $4.1 \mathrm{~kg}$, while the extraction took about $22 \mathrm{~min}$ and the sugarcane juice extracting machine having an efficiency of extraction of 83.7 $\%$, It can be seen that the efficiency of the machine was as high as expected. The effective extraction of the juice is done by sets of rollers; this is because since that the double sets of the roller are used in the arrangement which will effectively extract the juice in two-pass. This ensures higher efficiency and a capacity of $61.36 \mathrm{~kg} / \mathrm{hr}$. The extracting machine with a capacity of $61.36 \mathrm{~kg} / \mathrm{hr}$ was developed.

\section{CONCLUSION}

The aim of the construction was achieved with the ease of extraction of the juice from the sugarcane with a capacity of $61.36 \mathrm{~kg} / \mathrm{hr}$ which was developed and tested, the design of the sugarcane juice extracting machine possess simplicity in operation and maintenance as well as affordable with low running and maintenance costs with a reliable efficiency. When commercialized, the machine could go a long way in solving the problem of sugarcane juice domestically and also meeting the sugar requirement of the nation.

\section{REFERENCE}

Abdulkadir B. H, Matthew S. A, Olufemi A. O and Ikechukwu C. U (2009): The Design and Construction of Maize Threshing Machine Department of Mechanical Engineering, Federal University of Technology Minna, Niger State, Nigeria. AU J.T. 12(3): 199 -206
Alexandr F. A, Viachaslau K, Vladimir V. (2010): Driveline Systems of Ground Vehicles: Theory and Design. CRC Press: Taylor \& Francis Group, Boca Raton London

Cesar Benigno Granda Cotlear (2004): Sugarcane Juice Extraction and Preservation, and Long-Term Lime Pretreatment of Bagasse. A Dissertation by Submitted to Texas A\&M University in partial fulfillment of the requirements for the degree of Doctor of Philosophy

Khurmi R.S and Gupta J.K (2010): A Textbook of Machine Design. Eurasia Publishing House (P) Ltd., 7361, Ram Nagar, New Delhi - 110055

Kulkarni G K. (2005): Occupational health service - Need for competency development. Indian $\mathbf{J}$ Occup Environ Med 2005;9:5-6

Midwest Research Institute (1997): Sugarcane Processing. Emission Factor Documentation for AP-42, Section 9.10.1.1; final report. June 1997.

Olaoye, J. O. (2011): Development of a sugarcane juice extractor for small scale industries.

Journal of Agricultural Technology 7(4):931 -944.

Purseglove, J.W. 1988: Tropical crop: Monocotyledon. 3rd Edition. Published by Longman Pp. 300 - 333.

Rika Susan (2010): Article: A Household Sugarcane Juicer Only a Sweet Dream www.ezinearticles.com/?expert=Rika_Susa $\underline{\mathrm{n}}$

Tipler P. (2004): Physics for Scientists and Engineers: Mechanics, Oscillations and Waves, Thermodynamics (5th ed.). W. H. Freeman. ISBN 0-7167-0809-4

Singh Sadhu (2007): "Machine Design Data Book" Khanna Publishers 2-B Nath Market, Nai Sarak Delhi-110006

Wikipedia (2010): Sugarcane. http://en.wikipedia.org/wiki/Sugarcane 